\title{
Highly sensitive electrospun poly(HEMA-co-NMA)/BPDO nanofiber membranes for sensing metal ions in aqueous media
}

\author{
S. Chaudhuri ${ }^{1}$, C. M. Wu ${ }^{1 *}$, Y. C. Chiu ${ }^{2}$, D. H. Kuo ${ }^{1}$ \\ ${ }^{1}$ Department of Materials Science and Engineering, National Taiwan University of Science and Technology, 10607 Taipei, \\ Taiwan, ROC \\ ${ }^{2}$ Department of Chemical Engineering, National Taiwan University of Science and Technology, 10607 Taipei, Taiwan, ROC
}

Received 1 October 2020; accepted in revised form 26 November 2020

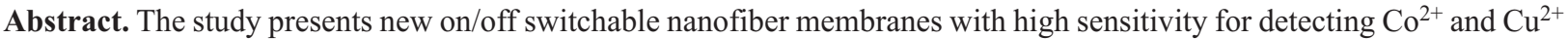
ions. The nanofiber membranes were fabricated by electrospinning (ES) the poly[(2-hydroxyethylmethacrylate-co- $N$-methylolacrylamide)] [poly(HEMA-co-NMA)] copolymer with different quantities of 2,2'-bipyridine-3,3'-diol (BPDO). Poly (HEMA-co-NMA) random copolymers with various molar ratios of the HEMA and NMA monomers were synthesized by free radical polymerization. The HEMA and NMA moieties were specifically selected to promote hydrophilicity and crosslinking reactions, which ultimately support a mechanically stable structure in aqueous media. ES nanofiber membranes S1-0.5, with a HEMA:NMA molar ratio of 77:23 and 0.5 wt \% of BPDO showed strong photoluminescence quenching upon exposure to $\mathrm{Co}^{2+}$ and $\mathrm{Cu}^{2+}$ ions at concentrations ranging from $10^{-7}$ to $10^{-4} \mathrm{M}$. Moreover, the nanofiber membranes exhibited reversibile on/off fluorescence emission properties upon the sequential addition of $\mathrm{Cu}^{2+}$ ions and ethylenediaminetetraacetic acid (EDTA). These results demonstrate a simple fabrication strategy for nanofiber membranes that have the potential to be effective for the real-time sensing of metal ions.
\end{abstract}

Keywords: smart polymers, polymer membranes, electrospinning, fluorescence, metal ion sensing

\section{Introduction}

Over the last few decades, the rapid growth of industrialization, mining, and agricultural activities has led to massive changes in aquatic and soil environments. The hazards of the contamination of natural water sources and ensuing adverse effects on flora, fauna, and human health raises many serious questions about safety. Metal ions are essential for human health but in very limited quantities. Thus, the World Health Organization (WHO) placed limits on the maximum permissible concentrations of each metal in an aqueous environment. Heavy metal ions such as mercury, copper, cobalt, iron, cadmium, zinc, and lead at concentrations that exceed permissible levels are highly toxic, with most showing carcinogenic effects, and are considered contaminants [1-3]. Moreover, they are not biodegradable, thus retain, recirculate, and accumulate in the environment and in humans and animals [2] to bioaccumulation and biomagnification. Thus, the detection and removal of these heavy metal ions are important objectives. Important performance attributes of sensors are high sensitivity and selectivity towards the desired metal analyte, rapid response times, and simple design.

Till now, many different types of metal ion sensors have been developed for better performance and costeffectiveness, including as- chemosensors, electrochemical sensors, optical sensors, and others [4-6].

${ }^{*}$ Corresponding author, e-mail: cmwu@mail.ntust.edu.tw (C) BME-PT 
Yet, optical sensors that use colorimetric and fluorescence readouts have received much attention because of their simplicity, fast response times, high selectivity and sensitivity, and localized tracing $[1,3,7]$. A wide range of materials has been explored for metal-ion sensing, such as organic molecules [8-11], conjugated polymers [12-16], nanomaterials [17-19], and quantum dots [20-22], among others. Bipyridine ligands are well known as metal-complex making probes for heavy metal ions. Some bipyridine molecules have been reported [23-26]. In this study, 2,2'bipyridine-3,3'-diol (BPDO) was selected because it is a well-studied probe for metal detection. This molecule has been explored with respect to its phototautomerization by photoinduced excited-state intramolecular double proton transfer (ESIDPT) [27-29]. Abou-Zied used steady-state and lifetime spectroscopic measurements to investigate the ground and excited state tautomerization of BPDO in different solvents and in confined nanocavities of cyclodextrins (CDs) [28]. Nag et al. [29] interrogated the effect of nanopores in porous gold nanoparticles on the ESIDPT by BPDO in aqueous environments. Rurack et al. [30] studied the fluorescence behaviors of BPDO. They worked on the influence of bivalent metal ions on the fluorescence spectra and kinetics of fluorescence decay. The complexation behaviors of metal ions in solutions containing water, alcohol, and acetonitrile were also explored [31]. Mandal et al. [32] investigated the anomalous behaviors of DMSO-water mixtures by using BPDO as a sensitive probe of the local micro-environment, as well as the potential application of BPDO as $\mathrm{Zn}^{2+}$ ion tracing. However, most investigations require the BPDO probe to be in solution, making it difficult to reuse as a sensor [3]. Moreover, it is challenging to manufacture a simple sensor that employs a solution-based probe. As a result, researchers explored immobilizing probes onto solid materials. Such solid sensors have reduced active sensing densities and also present diffusion limitations for metal ions in reaching the sensor surface [1, 33-35]. Polymers are promising host materials for immobilizing the sensing probes. The host polymer can be applied in different forms, such as coating, film, and fiber. However, the coating or film cannot provide high sensing performance, whereas the nanofiber has a larger surface area, thereby enhancing the sensing ability. To the best of our knowledge, the immobilization of BPDO on nanofibers for metal sensing has not been explored yet.
There are many different methods used to prepare nanofibers, such as drawing, template synthesis, freeze-drying, phase separation, self-assembly, and electrospinning. However, fiber drawing is mainly used for selective high viscoelastic materials and is not suitable for small diameter nanofibers. Template synthesis and phase separation have limitations to produce long, continuous fiber. Freeze drying is mainly related to porous nanofibers, although uneven porosity limits their use. Although self-assembly represents an attractive and feasible strategy for manufacturing nanofibers, it is not cost-effective. Nanofibers produced by electrospinning have a wide range of diameters, are relatively inexpensive, and can be applied to a variety of materials with suitable solvents. In addition, due to its ease of operation and the ability to produce nanofiber membranes with tunable morphology, it is a simple, unique and versatile technology that has been widely used in recent work. [36-42]. The high surface area to volume ratio of the resulting nanofiber membranes makes these materials attractive for various applications. For example, Chen et al. [43] used electrospun (ES) nanofiber membranes of $\mathrm{ZnO}$ for photocatalysis, UV shielding, and antibacterial applications. Babel et al. [44] prepared co-axial ES nanofiber membranes to fabricate field-effect transistors. Our research group used functionalized polyvinylidene fluoride ES nanofiber membranes to study acoustic-electric conversion and piezoelectric properties $[45,46]$. Naseem functionalized recycled cellulose triacetate nanofiber membranes for oil-water separation and interfacial water evaporation [47, 48]. Chala prepared melt ES polylactic acid nanofiber membranes for water evaporation [49]. Some important applications of electrospinning are tissue engineering [50], reinforcements [51], heavy metal detection [52], actuators [53], water management [54], drug release [55], and thermal insulation [56]. However, few studies have reported that fluorescent ES nanofiber membranes can be used for the detection of heavy metals. Chen et al. [57] prepared multifunctional luminescent ES nanofiber membranes as chemosensor filters for sensing $\mathrm{pH}$, temperature, and mercury $\left(\mathrm{Hg}^{2+}\right)$ ions. In addition, the fluorescent chemosensory filter membrane prepared by ES nanofiber membranes of poly(2-hydroxyethyl methacrylate- $\mathrm{co}-\mathrm{N}$-methylol acrylamide-co-rhodamine derivative) with high sensitivity for $\mathrm{pH}$ and $\mathrm{Hg}^{2+}$ detection were reported [58]. Wang et al. [59] developed a novel sensing material poly(methyl 
methacrylate-co-1,8 napthalimide derivative), which was subsequently used to form an ES nanofiber membrane that sensed and adsorbed $\mathrm{Cu}^{2+}$ ions in an aqueous solution. Wang et al. [60] prepared poly (acrylic acid-pyrene methanol) ES nanofiber membranes that were sensitive to $\mathrm{Fe}^{3+}$ and $\mathrm{Hg}^{2+}$ ions. Thus, we hypothesized that BPDO immobilized onto such nanofiber membranes could both absorb high quantities of water and promote contacts metal ions while also retaining its shape during and after the testing.

In order to immobilize the sensing probe on the polymer nanofiber membrane, various host polymers have been studied, such as PLLA [49], PMMA [59], HEMA [58], PAA [60], NMA [57, 58]. Among these host polymers, poly (2-hydroxyethyl methacrylate), or PHEMA, is extensively used for different water absorption applications. Researchers have applied PHEMA to sense analytes in an aqueous solution because of its superhydrophilicity. Thus, it can be blended with a sensory probe molecule and still absorb high quantities of an aqueous solution. Yet, the high hydrophilicity of PHEMA materials that integrate sensing probes can easily dissolve, thus compromising the long-term stability of the material in aqueous solutions. Poly( $N$-methylolacrylamide), or PNMA, is a well known cross-linking agent that cross-links with molecules by its terminal hydroxyl group. In our previous work on thermoresponsive polymers, we included HEMA, NMA, and the thermoresponsive monomer $N$-isopropylacrylamide (NIPAAm) to prepare a random thermoresponsive tri-copolymer for moisture management applications [61]. Other research groups have also explored PNMA-based cross-linked ES nanofiber membranes and films in the design and preparation of copolymers for applications in aqueous media [58,62].

Considering all these issues, we developed ES nanofiber membranes composed of copolymers consisting of HEMA and NMA and blended with the metalion sensing probe, BPDO. Further, the membrane was cross-linked to achieve structural stability in aqueous media. The copolymer was characterized by proton nuclear magnetic resonance $\left({ }^{1} \mathrm{H}\right.$ NMR $)$ spectroscopy and Fourier-transform infrared spectroscopy (FTIR) to establish structure and composition. Initial selectivity tests were conducted by acquired the photoluminescence (PL) spectra of BPDO solutions containing different metal ions. The morphologies of nanofiber membranes were studied by a field-emission scanning electron microscopy (FESEM). UV-vis absorption and PL spectroscopy were conducted on solutions of BPDO, and ES nanofiber membranes were used to detect various concentrations of selected heavy metal ions.

\section{Experimental}

\subsection{Materials}

2-Hydroxyethyl methacrylate, HEMA (97\%), was provided by Acros, Morris Plains, NJ, USA. HEMA was stored at $4{ }^{\circ} \mathrm{C}$ before usage and passed through an alumina $\left(\mathrm{Al}_{2} \mathrm{O}_{3}\right)$ column for purification before polymerization. $N$-methylolacrylamide, NMA $(>98 \%)$, and 2,2'-azobis(2-methylpropionitrile), AIBN ( $>99 \%$ ), were purchased from the Tokyo Chemical Industry Co., Tokyo, Japan, and Aencore, Surrey Hills, Australia, respectively. AIBN was recrystallized with an ethanol solution prior to usage. Methanol, $\mathrm{MeOH}$ (99.9\%) was purchased from Fisher Scientific Co., Pittsburgh, Pennsylvania, USA. Nitrate salts of cobalt, mercury, magnesium, nickel, and lead were purchased from Acros, Morris Plains, NJ, USA. Copper sulfate and chloride salts of iron, potassium, and zinc were purchased from Showa Chemical Industry Co. Ltd., Tokyo, Japan. 2,2'-bipyridine-3,3'-diol (98\%). BPDO was purchased from Sigma Aldrich, St. Louis, Missouri, USA.

\subsection{Synthesis of poly(HEMA-co-NMA)}

The random copolymer, poly(HEMA-co-NMA), was synthesized by free-radical copolymerization of HEMA and NMA monomers as shown in Figure 1.

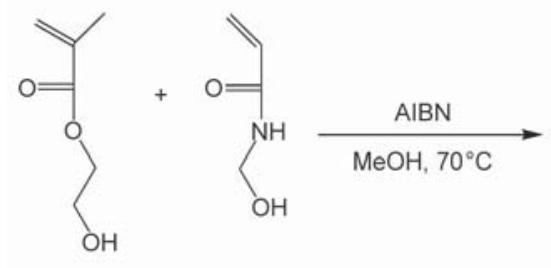

a) HEMA NMA
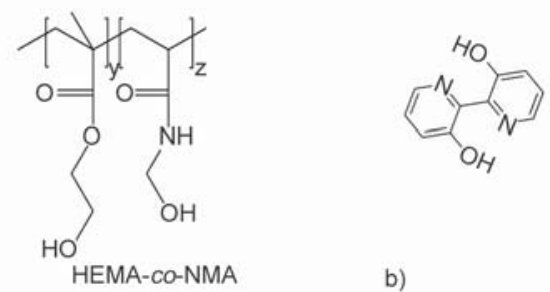

b)

Figure 1. (a) Schematic of the synthesis reaction of poly(HEMA-co-NMA). (b) Structure of 2,2'-bipyridine-3,3'-diol (BPDO). 
Table 1. Compositions and properties of poly(HEMA-coNMA) copolymers.

\begin{tabular}{|l|c|c|c|}
\hline Sample & $\begin{array}{c}\text { Feed molar ratio: } \\
\text { HEMA:NMA } \\
\text { [\%] }\end{array}$ & $\begin{array}{c}\text { Experimental molar } \\
\text { ratio: HEMA:NMA } \\
\text { [\%] }\end{array}$ & $\begin{array}{c}\text { Viscosity } \\
{[\text { Pa } \cdot \mathbf{s}]}\end{array}$ \\
\hline S1 & $77: 23$ & $75.7: 24.3$ & 0.0579 \\
\hline S2 & $91: 9$ & $91.4: 8.6$ & 0.0423 \\
\hline
\end{tabular}

A similar synthesis process has been reported [6163]. The two different monomer ratios of this bicopolymer are denoted as $\mathrm{S} 1$ and $\mathrm{S} 2$, and are listed in Table 1. Feed molar ratios of HEMA and NMA of 77:23 and 91:9 were both considered based on previous work to achieve sufficient cross-linking and yield materials that do not dissolve in water over the timeframe of the experiment $[58,62]$. The monomers, HEMA and NMA, and initiator, AIBN, were dissolved in $\mathrm{MeOH}$ in a two-necked round-bottomed flask. Nitrogen was bubbled through the reaction mixture for $30 \mathrm{~min}$ for degassing, and subsequently, the mixture was refluxed in an oil bath at $70^{\circ} \mathrm{C}$ for $24 \mathrm{~h}$. The polymerization reaction was quenched by exposure to air. The resultant mixture was poured dropwise into diethyl ether under vigorous stirring, and the precipitate was filtered and dried at $35^{\circ} \mathrm{C}$ under vacuum for $24 \mathrm{~h}$. Random copolymers with the two aforementioned molar ratios of HEMA and NMA were obtained.

\subsubsection{Synthesis of $\mathrm{S} 1$}

A reaction mixture containing $4000 \mathrm{mg}$ (30.74 mmol) of HEMA, $932 \mathrm{mg}$ (9.22 mmol) of NMA, $16.4 \mathrm{mg}$ $(0.10 \mathrm{mmol})$ of AIBN, and $20 \mathrm{ml}$ of $\mathrm{MeOH}$ was used to obtain $3150 \mathrm{mg}$ solid white polymer $(63.7 \%$ yield). ${ }^{1} \mathrm{H}$ NMR ( $d$-DMSO, $\left.600 \mathrm{MHz}\right): \delta[\mathrm{ppm}]$ : 0.7-2.1 (peak a, b, c), 3.5-3.6 (peak e), 3.7-4.1 (peak d), 4.2-4.6 (peak h), 4.8-5.1 (peak f), 5.3-5.6 (peak i), 8.1-8.4 (peak g).

\subsubsection{Synthesis of $S 2$}

A reaction mixture containing $5000 \mathrm{mg}(38.42 \mathrm{mmol})$ of HEMA, $388 \mathrm{mg}$ ( $3.84 \mathrm{mmol})$ of NMA, $16.4 \mathrm{mg}$ $(0.10 \mathrm{mmol})$ of AIBN, and $20 \mathrm{ml}$ of $\mathrm{MeOH}$ was used to obtain $3690 \mathrm{mg}$ solid white polymer $(68.3 \%$ yield). ${ }^{1} \mathrm{H}$ NMR ( $d$-DMSO, $\left.600 \mathrm{MHz}\right): \delta[\mathrm{ppm}]$ : 0.8-2.1 (peak a, b, c), 3.5-3.6 (peak e), 3.7-4.1 (peak d), 4.2-4.7 (peak h), 4.8-5.1 (peak f), 5.3-5.6 (peak i), 8.1-8.4 (peak g).

\subsection{Fabrication of cross-linked ES nanofiber membranes}

Poly(HEMA-co-NMA) $\left(200 \mathrm{mg} \cdot \mathrm{ml}^{-1}\right)$ of S1 and S2 samples were blended with BPDO probe at 0.25 , 0.50 , and $1.00 \mathrm{wt} \%$ (with respect to the polymer) in $\mathrm{MeOH}$ at room temperature, and the solution was stirred for 3-4 hours. After complete dissolution, the solution was ready for electrospinning. A single capillary spinneret electrospinning device was used to obtain ES nanofiber membranes consistent with reported literature $[47,58,62]$. The blended polymer solution was injected into a metallic needle using a syringe pump (KDS 101 series, KD Scientific, USA) at a constant feed rate of $0.02 \mathrm{~mL} \cdot \mathrm{h}^{-1}$. The tip of the metallic needle was connected to a grounded electrostatic controller (SM 4030-24 NIR, You-Shang Technical Corp., Taiwan) that was set to $20 \mathrm{kV}$ during the electrospinning process. A flat piece of aluminum foil was placed $15 \mathrm{~cm}$ from the tip of the needle (i.e., working distance or tip-to-collector distance) to collect nanofibers. A composite material with sufficient mechanical strength was prepared by electrospinning nanofibers directly onto a polyester spunbonded nonwoven fabric. Composite material with dimensions of $8 \mathrm{~cm} \times 2 \mathrm{~cm}$ and area weight of $5.37 \mathrm{mg} \cdot \mathrm{cm}^{-2}$, showing a tensile strength of $33.32 \mathrm{~N}$. All of the electrospinning experiments were conducted at room temperature at a relative humidity of approximately $40 \%$. The ES nanofiber membranes were annealed at $120^{\circ} \mathrm{C}$ for $24 \mathrm{~h}$ in an oven for chemical cross-linking. The BPDO-incorporated ES nanofiber membranes were prepared by blending different weight percentages of BPDO. The samples blended with $0.25,0.50$, and $1.00 \mathrm{wt} \%$ (with respect to polymer weight) $\mathrm{BPDO}$ with $\mathrm{S} 1$ polymer samples are referred to as S1-0.25, S1-0.50, and S1-1.00, respectively.

\subsection{Characterization}

${ }^{1} \mathrm{H}$ NMR spectra were recorded on a Bruker Avance III, HD-600 MHz spectrometer (Bruker, Billerica, Massachusetts, USA) using digital quad detection (DQD) acquisition mode. The solvent was d-dimethyl sulfoxide (DMSO- $d_{6}$ ) as the solvent, and all measurements were conducted at $27^{\circ} \mathrm{C}$ with a $5 \mathrm{~mm}$ probe and delay time of $2 \mathrm{~s}$. Chemical shifts $(\delta)$ are presented as parts per million [ppm]. FTIR spectroscopy was 
conducted on an FTIR spectrometer (JASCO FT/IR4600, JASCO, Tokyo, Japan) to provide insights into the bonds of functional groups. FTIR spectra were recorded over a wavenumber range of $4000-500 \mathrm{~cm}^{-1}$ with a spectral resolution of $4 \mathrm{~cm}^{-1}$. Each spectrum represents 64 signal-averaged scans. Powder samples for FTIR were prepared by grinding by mortar and pestle without potassium bromide or other alkali halides and dried for $1 \mathrm{~h}$ in an oven at $60^{\circ} \mathrm{C}$. A UVvisible absorption spectrometer (JASCO V-670, JASCO, Tokyo, Japan) was used to monitor variations in optical absorbance following the addition of solutions containing metal ions. Similarly, changes in photoluminescence (PL) were measured on a PL spectrophotometer (JASCO, Tokyo, Japan) with a light source of Xe arc-lamp. The excitation wavelength was considered as $340 \mathrm{~nm}$, and the spectrum range was between 370 to $800 \mathrm{~nm}$. For PL, fabricated ES nanofiber membranes were inserted into a cuvette and fixed by adhesive tape such that their surfaces faced the excitation light source. Subsequently, solutions containing metal ions at $10^{-7}$ to $10^{-4} \mathrm{M}$ were then added, and the changes in PL were measured as reported previously $[63,64]$. The viscosity of the polymer solution used for electrospinning was measured at room temperature using a modular compact rheometer (MCR-102, Anton Paar Taiwan Co. Ltd, Taipei, Taiwan). The morphologies of the ES nanofiber membranes samples were characterized by FESEM (JEOL JSM-6500F, Tokyo, Japan). The samples were sputtered with Au before imaging. Electron microscopy images were captured at an accelerating voltage of $15 \mathrm{kV}$. The average diameter of nanofibers was calculated by Motic Images Plus 2.0 software. The mechanical property of the composite samples were tested in a universal testing machine (COMETECH QC-508M2, Cometech, Taichung, Taiwan) at room temperature.

\section{Results and discussion}

\subsection{Structural characterization}

The chemical structures and composition of poly (HEMA-co-NMA) were characterized by using NMR spectroscopy. Chemical shifts at 2.5 and $3.3 \mathrm{ppm}$ are observed for the solvent DMSO- $d_{6}$ and $\mathrm{H}_{2} \mathrm{O}$, respectively. Peak assignments for the ${ }^{1} \mathrm{H}$ NMR chemical shifts of HEMA and NMA are as follows. For HEMA, the peaks at 4.8-5.1 ppm (f), 3.5-3.6 ppm (e), and $3.7-4.1 \mathrm{ppm}$ (d) are assignable to the terminal hydroxyl, the methylene neighbor of the hydroxyl, and the methylene neighbor of the oxygen, respectively. For NMA, peaks at 5.3-5.6 ppm (i), 8.1-8.4 ppm (g), and 4.2-4.6 ppm (h) correspond to the terminal hydroxyl, secondary amine, and methylene group near hydroxyl of NMA, respectively. Peaks at 0.7-2.1 ppm $(a, b, c)$ correspond to alkyl chains of the backbone. These results compare well with previous work [62]. Peaks are observed for all moieties in both target compounds and reveal successful polymerization. The feed molar ratios of HEMA and NMA monomers for S1 and S2 are approximately 10:3 and 10:1, respectively. Experimental molar ratios are calculated by integrating the areas of the ${ }^{1} \mathrm{H}$ NMR peaks (f) and (i). As shown in Table 1, the experimental molar ratios are consistent with the feed molar ratios.

The FTIR spectra of the S1 and S2 copolymers establish the bonds present in the copolymer. Absorption bands that appeared within the range of 3200$3500 \mathrm{~cm}^{-1}$ originate from $\mathrm{O}-\mathrm{H}$ stretches in the HEMA, and NMA moieties and $\mathrm{N}-\mathrm{H}$ stretches in the NMA moieties. This peak was broader for the S1 polymer than for the S2 polymer because the S1 polymer had higher quantities of NMA. The peaks at 2942 and $1710 \mathrm{~cm}^{-1}$ arose from $-\mathrm{CH}_{2}$ and $\mathrm{C}=\mathrm{O}$ stretching in the HEMA moiety, respectively. The absorption peaks at 1665 and $1542 \mathrm{~cm}^{-1}$ correspond to $\mathrm{C}=\mathrm{O}$ stretches and $\mathrm{N}-\mathrm{H}$ bending, respectively, in the NMA moiety. The peaks are similar to the reported literature also [65-68]. The presence of all these bonds establishes the successful synthesis of copolymers with two different monomer ratios.

\subsection{Metal ion selection by BPDO}

Figure 2 shows the PL spectra collected from BPDO in $\mathrm{MeOH}$ solutions containing various metal ions at $10^{-4} \mathrm{M}$, using excitation at $340 \mathrm{~nm}$ at room temperature. A transparent BPDO solution with concentration $10^{-5} \mathrm{M}$ was prepared by dissolving yellow-colored whisker-like BPDO molecules in $\mathrm{MeOH}$. The emission peak of the BPDO solution (i.e. without any metal ions) was at $474 \mathrm{~nm}$. The fluorescence intensity slightly increased after adding $\mathrm{Fe}^{3+}, \mathrm{Hg}^{2+}$, $\mathrm{Pb}^{2+}, \mathrm{K}^{+}, \mathrm{Zn}^{2+}$ ions but remained the same or was slightly quenched after adding $\mathrm{Mg}^{2+}$ and $\mathrm{Ni}^{2+}$. While the fluorescence of BPDO in $\mathrm{MeOH}$ changes with these metal ions, the changes are not significant enough for practical sensing applications. By comparison, the fluorescence of BPDO was substantially quenched in the presence of $\mathrm{Cu}^{2+}$ and $\mathrm{Co}^{2+}$ ions due to the chelation of $\mathrm{Cu}^{2+}$ and $\mathrm{Co}^{2+}$ ions with the 


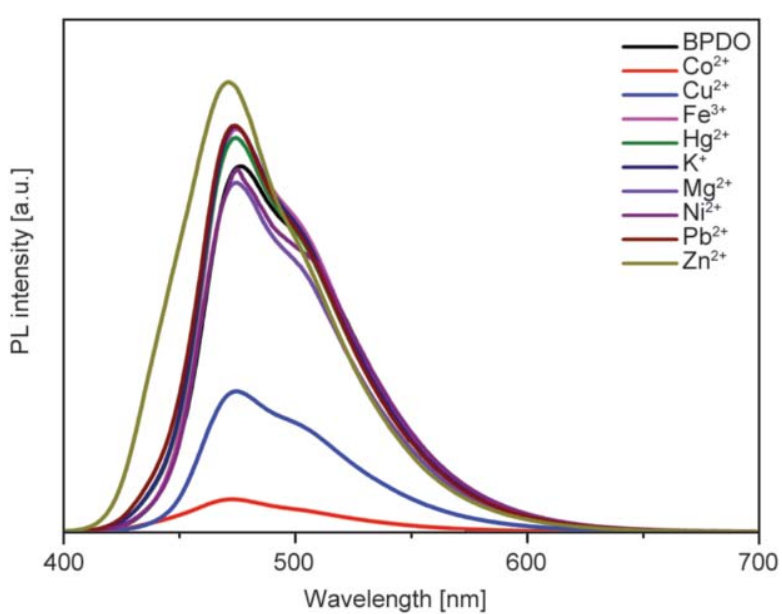

Figure 2. PL spectra of BPDO in $\mathrm{MeOH}$ solution without and with various metal ions.

BPDO probe. These strong changes in fluorescence prompted further exploration of the sensing behavior of the BPDO molecule with respect to these ions.

\subsection{Morphology of ES nanofiber membranes}

Figure 3 shows the FESEM images of ES nanofiber membranes produced from S1, S1-0.5, and S2 polymer samples. ES nanofiber membranes that were not cross-linked dissolved in water shortly after immersion. The area weight of the ES nanofiber membranes of S1, S1-0.5, and S2 was 2.94, 2.93, and $2.84 \mathrm{mg} \cdot \mathrm{cm}^{-2}$. The average diameters of the nanofibers in the cross-linked ES nanofiber membranes prepared from S1, S1-0.5, and S2 were $654 \pm 147$, $648 \pm 122$, and $478 \pm 118 \mathrm{~nm}$, respectively. The diameter of the ES nanofiber prepared from the S2 polymer solution was considerably smaller than those prepared from S1 and S1-0.5 polymers. This was presumably due to the lower molecular weight of S2, which manifested in the lower viscosity of S2 than $\mathrm{S} 1$ when dissolved in the same solvent and at the same concentration. Moreover, the diameters of nanofibers prepared from $\mathrm{S} 1$ and $\mathrm{S} 1-0.5$ polymers were similar. This affirms that incorporating the BPDO probe did not affect nanofiber morphology. The resulting fibers were smooth, uniform, and nodporous. Any chance that porosity formed by the accelerated evaporation of methanol solvent, which has a low boiling point, was ultimately abated by consistently maintaining relative humidity at approximately $40 \%$ during electrospinning. Moreover, the S1 and S1-0.5 nanofibers swelled (to diameters of $1450 \pm 298$ and $1470 \pm 272 \mathrm{~nm}$, respectively) after immersion in water but still retained fiber-like structures. Therefore, the morphology of the nanofiber membrane before the test was like that of a dry sample similar to Figure $3 a$ and $3 b$ whereas after test it showed a swelled, water-soaked structure similar to Figure $3 \mathrm{~d}$ and $3 \mathrm{e}$. This swelling arises from the HEMA moiety that is superhydrophilic, and thus absorbs high quantities of water. This adsorption, in-turn, increases the efficiency of metal-ion absorption. By comparison, NMA plays an important role in retaining a fiber-like structure with a high surface-to-volume ratio. Higher amounts of NMA helped to retain structure by enabling greater cross-linking densities. On the contrary, nanofibers prepared from S2 did not dissolve in water after undergoing a similar cross-linking process to the S1 nanofibers, but its morphology was disrupted. The nano-fibrous morphology changed into a film-like structure at many locations, suggests that lower cross-linking densities result in structures with aggregated film-fiber mixtures that ultimately reduce the surface-to-volume ratio.

\subsection{Detection of different concentrations of metal ions of BPDO}

Figure 4 shows the UV-vis and PL spectra obtained from solutions of BPDO in $\mathrm{MeOH}$ solutions with concentrations of $\mathrm{Co}^{2+}$ ranging from $10^{-7}$ to $10^{-4} \mathrm{M}$. The UV-vis spectra show that increased concentrations of $\mathrm{Co}^{2+}$ more effectively quenched the maximum absorbance peak at $340 \mathrm{~nm}$. This is attributable to the $\pi-\pi^{*}$ transition band. At a $\mathrm{Co}^{2+}$ concentration of $5 \cdot 10^{-5} \mathrm{M}$ an additional absorption band at $417 \mathrm{~nm}$ was observed. At a $\mathrm{Co}^{2+}$ concentration of $10^{-4} \mathrm{M}$, the intensity completely shifted to this additional absorption band. The PL spectra of the $\mathrm{Co}^{2+}$-containing solutions show that $\mathrm{Co}^{2+}$ ions cause a decrease in fluorescence intensity, producing a prominent hypochromic shift at increased ion concentrations. But the maximum intensity of the fluorescence peak occurred at $474 \mathrm{~nm}$ for all $\mathrm{Co}^{2+}$ concentrations, without any red or blue shift. Almost complete fluorescence quenching of is observed at $\mathrm{Co}^{2+}$ concentrations of $10^{-4} \mathrm{M}$, which results from the formation of a $\mathrm{co}$ BPDO complex. Stephenson and Hardie explained that salts containing $\mathrm{Co}^{2+}$ ions produce a complex with three BPDO equivalents due to the conversion of $\mathrm{Co}^{2+}$ to inert $\mathrm{Co}^{3+}[69]$.

The UV-vis spectra in Figure 5a reveal that increased concentrations of $\mathrm{Cu}^{2+}$ ions cause greater quenching of the maximum absorbance peak of BPDO at $340 \mathrm{~nm}$, similar to $\mathrm{Co}^{2+}$ ions. Moreover, an additional absorption band forms at $\mathrm{Cu}^{2+}$ concentrations of 

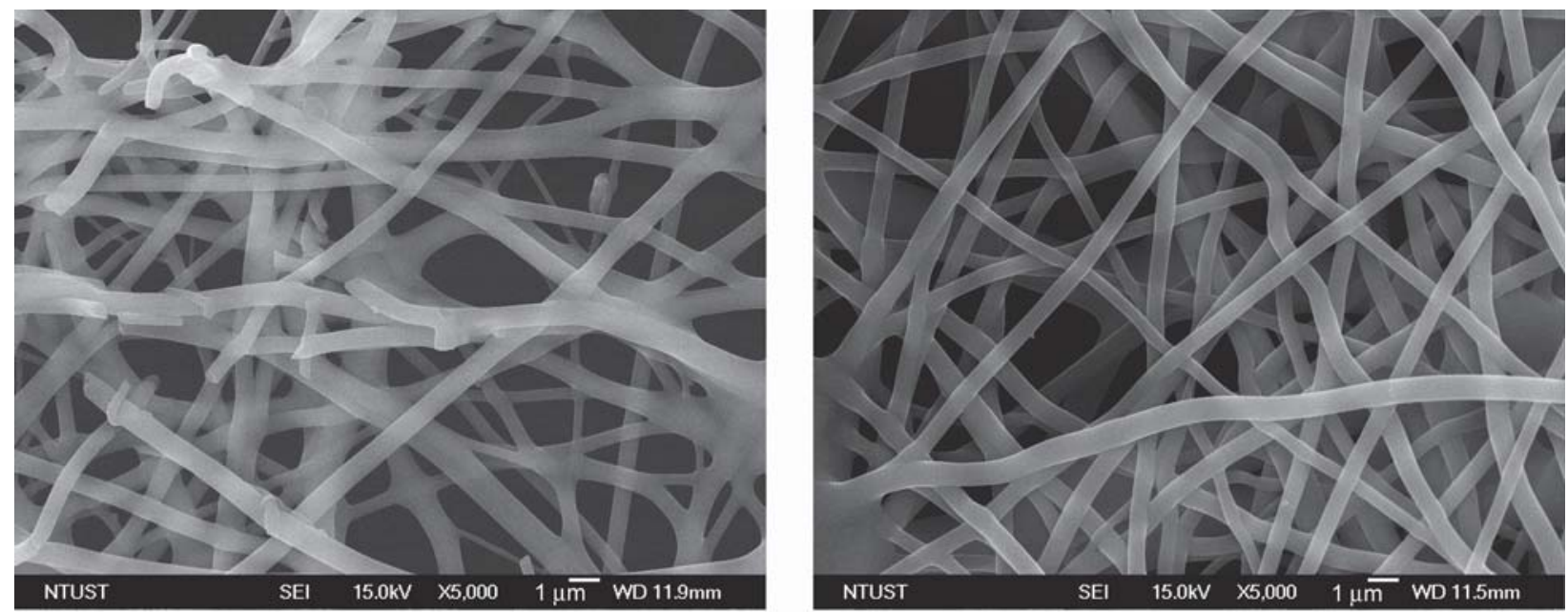

a)

b)
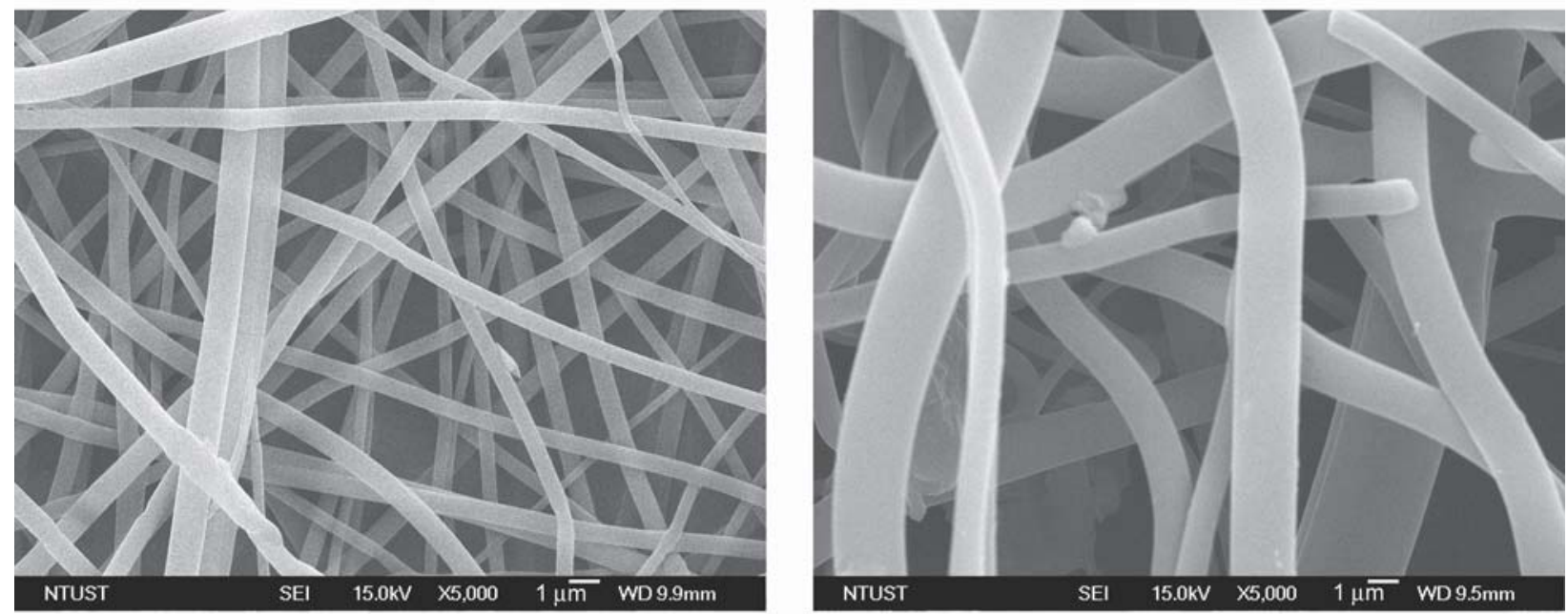

c)

d)
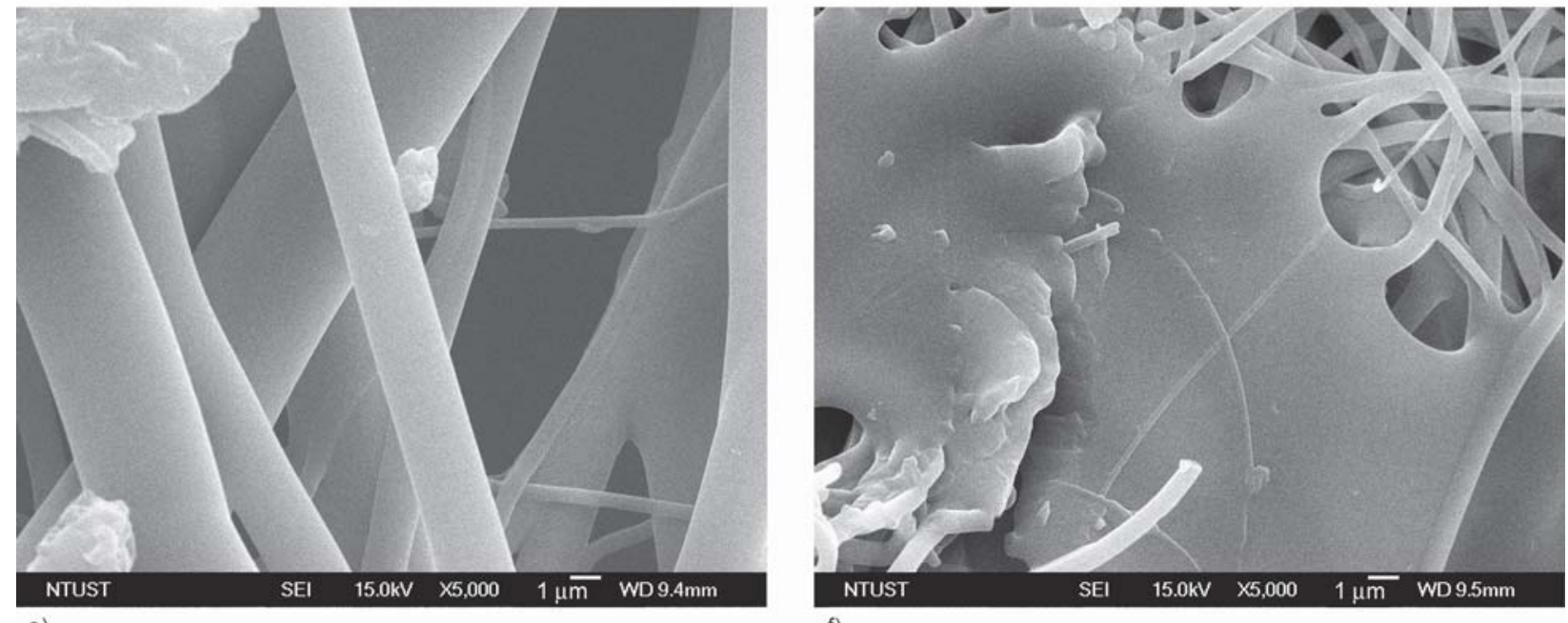

e)

f)

Figure 3. FESEM images of dry (a) S1, (b) S1-0.5, (c) S2 and water-soaked (d) S1, (e) S1-0.5, (f) S2 ES nanofiber membranes.

$5 \cdot 10^{-5} \mathrm{M}$, and at $10^{-4} \mathrm{M}$ of $\mathrm{Cu}^{2+}$, the maximum absorption peak undergoes a redshift. This additional new band originates from metal to ligand charge transfer [70]. While the UV-vis absorption behavior of $\mathrm{Cu}^{2+}$ ions is similar to that of $\mathrm{Co}^{2+}$ ions, the shifted maximum absorption peak occurs at $397 \mathrm{~nm}$, which is nearer to the original band when compared to $417 \mathrm{~nm}$ wavelength of the additional absorption band from $\mathrm{Co}^{2+}$ ions. Titration with $\mathrm{Cu}^{2+}$ ions also reduces the fluorescence intensity of the BPDO probe 

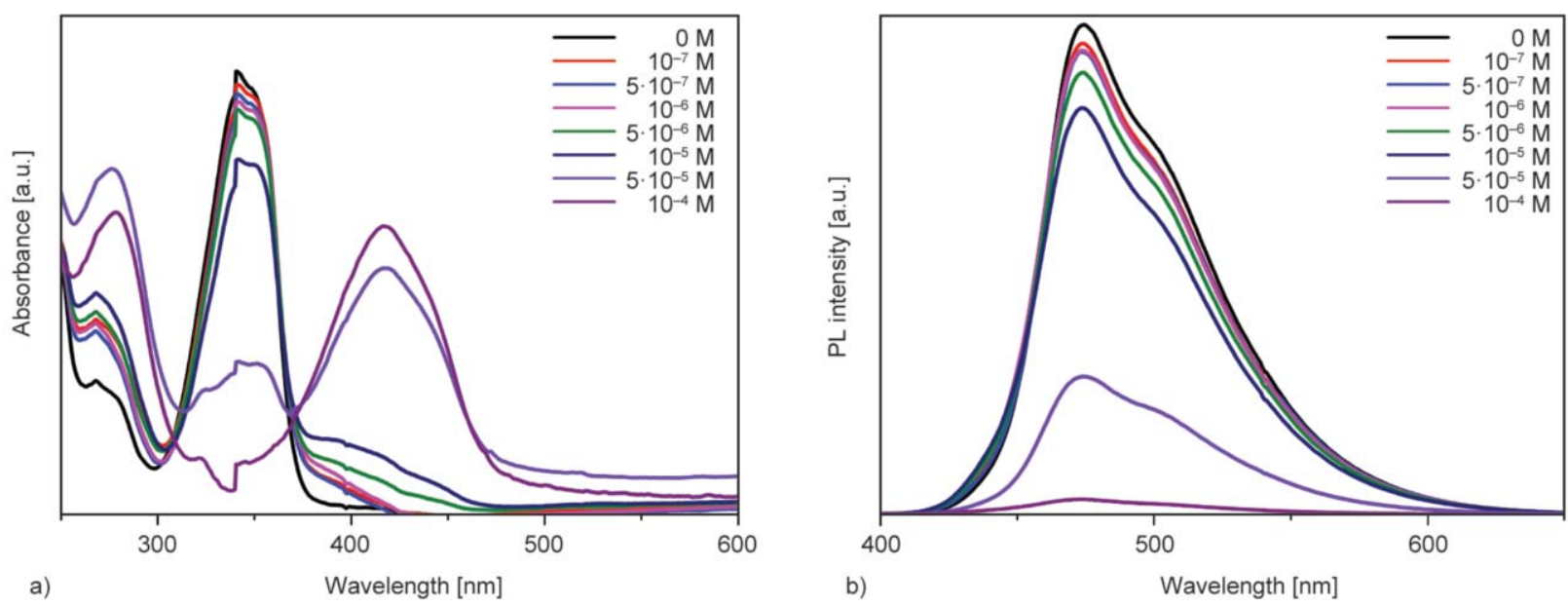

Figure 4. The (a) UV-vis and (b) PL spectra of BPDO in $\mathrm{MeOH}$ solution without and with different concentrations of $\mathrm{Co}^{2+}$ ions.
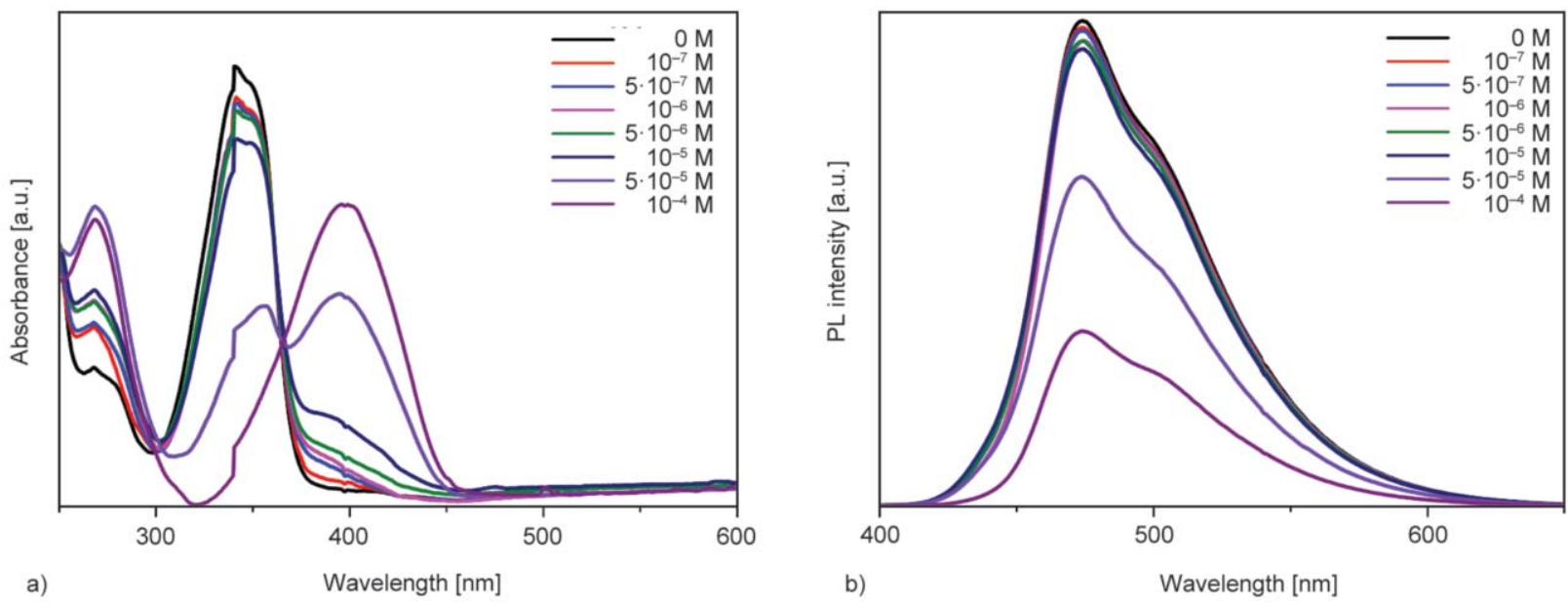

Figure 5. The (a) UV-vis and (b) PL spectra of BPDO in $\mathrm{MeOH}$ solutions without and with various concentrations of $\mathrm{Cu}^{2+}$ ions.

in an aqueous solution in a concentration-dependent manner (Figure 5b). The maximum fluorescence peak was observed at $474 \mathrm{~nm}$ for all $\mathrm{Cu}^{2+}$ concentrations without any red or blue shift. Studies by Rurack et al. [30] on $\mathrm{Cu}^{2+}$ ions observed a similar trend of decreased fluorescence without a compensating fluorescence lifetime. This phenomenon was explained by a reduced quantity of fluorescence emitting BPDO molecules because of the generation of $\mathrm{Cu}$-BPDO complex based on the paramagnetic properties of $\mathrm{Cu}^{2+}[70]$. Moreover, this result aligns with the Irving-Williams series that shows $\mathrm{Cu}^{2+}$ ion complexes have higher affinities due to electrostatic forces irrespective of the nature of the ligands.

\subsection{Detection of metal ions by S1-0.5 ES nanofiber membranes}

Figure 6 illustrates the changes in the PL (fluorescence) emission spectra of S1-0.5 ES nanofiber membranes upon exposure to various concentrations of $\mathrm{Co}^{2+}$ and $\mathrm{Cu}^{2+}$ ions in an aqueous solution. The ' $0 \mathrm{M}$ ' concentration indicates aqueous solutions without metal ions. S1-0.5 ES nanofiber membranes show a maximum emission peak at $469 \mathrm{~nm}$ that solely originates from the BPDO molecule. Figure 6a depicts the sensitivity of S1-0.5 to detect $\mathrm{Co}^{2+}$ ions at concentrations of $10^{-7}$ to $10^{-4} \mathrm{M}$. The PL intensity reduces with the increasing concentrations of $\mathrm{Co}^{2+}$ ions. Besides the maximum emission peak $\left(\lambda_{\max }\right)$ at $476 \mathrm{~nm}$, an additional peak is observed at $506 \mathrm{~nm}$ in the solution containing $10^{-7} \mathrm{M}$ of $\mathrm{Co}^{2+}$. Both peaks reduce in intensity with increasing $\mathrm{Co}^{2+}$ concentration, and at $10^{-5} \mathrm{M}$ of $\mathrm{Co}^{2+}$, both peaks almost merge into a single broadened peak. The $\lambda_{\max }$ undergoes a redshift from 469 to $476 \mathrm{~nm}$ at $10^{-7} \mathrm{M}$ of $\mathrm{Co}^{2+}$. Yet, no further shifts were observed upon increasing at $\mathrm{Co}^{2+}$ concentrations up to $10^{-4} \mathrm{M}$. The considerable changes in the intensity between $\mathrm{Co}^{2+}$ concentrations 

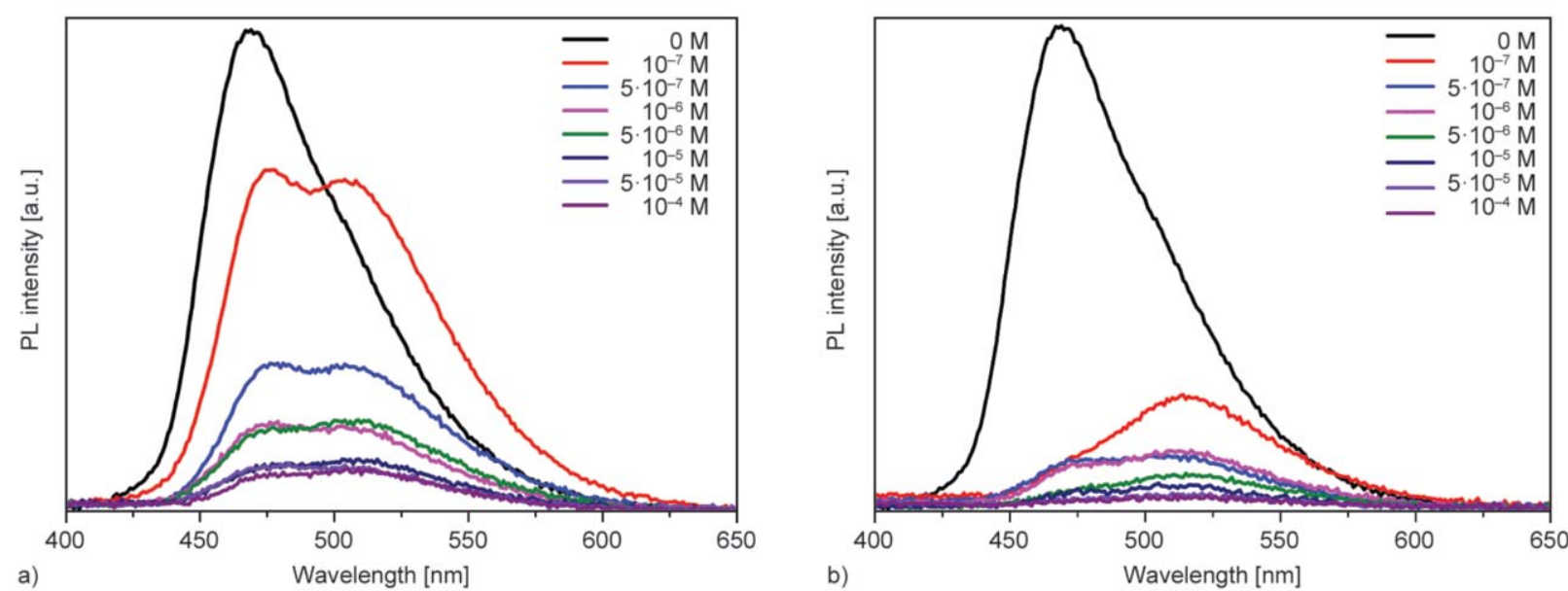

Figure 6. The PL spectra of S1-0.5 ES nanofiber membranes in aqueous solutions containing (a) $\mathrm{Co}^{2+}$ and (b) $\mathrm{Cu}^{2+}$ ions at concentrations ranging from $10^{-7}$ to $10^{-4} \mathrm{M}$.

of $10^{-7}$ to $10^{-4} \mathrm{M}$ establish a high sensitivity of the nanofiber membranes towards $\mathrm{Co}^{2+}$ ions. Thus, S1-0.5 nanofiber membranes appear to be promising for practical applications in sensing.

Figure $6 \mathrm{~b}$ shows the sensitivity of S1-0.5 against $\mathrm{Cu}^{2+}$ ions at concentrations from $10^{-7}$ to $10^{-4} \mathrm{M}$. PL intensity reduces substantially with increasing $\mathrm{Cu}^{2+}$ concentration. Such fluorescence quenching is anticipated because of the reduced number of BPDO molecules due to the formation of non-fluorescent $\mathrm{Cu}$-BPDO complexes, as mentioned earlier. As described by Reynal et al. [70], $\mathrm{Cu}^{2+}$ ions link to BPDO molecules via a nitrogen atom in the bipyridine and an oxygen atom in the hydroxyl groups. This increases the stabilities of $\mathrm{H}$-bonds between the amino and hydroxyl groups. Moreover, the steric hindrance of two hydroxyl groups in 3,3' facilitates chelation. The high surface area of S1-0.5 nanofiber enables

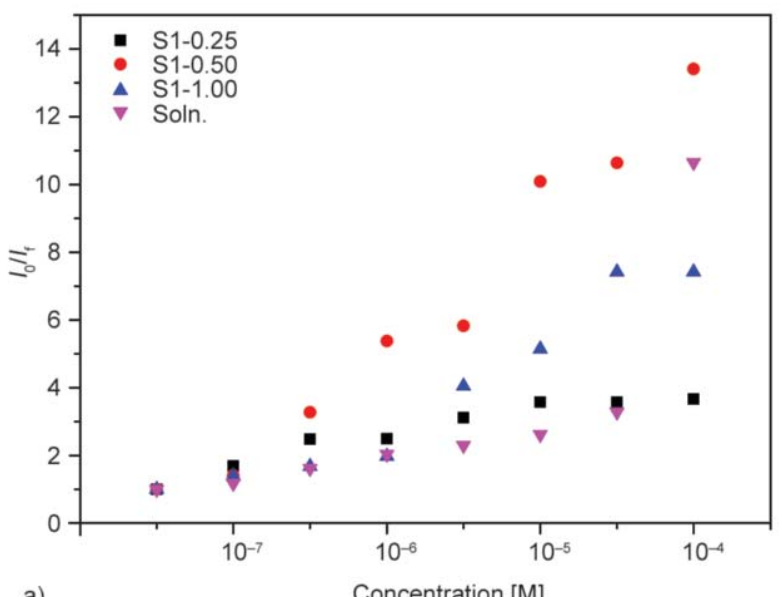

BPDO molecules within the nanofibers to easily chelate (as mentioned above) with $\mathrm{Cu}^{2+}$ ions absorbed from the water. Moreover, nanofiber membranes can be recycled and reused. By comparison, BPDO powder is challenging to recycle.

\subsection{Comparison of the fluorescence responses of ES nanofiber membranes and BPDO in solution}

Figure 7 summarizes the variations in PL intensity with $\mathrm{Co}^{2+}$ and $\mathrm{Cu}^{2+}$ ion concentration for all the three nanofiber membranes and BPDO in $\mathrm{MeOH}$ solution. Quantitative comparisons of fluorescence quenching and PL intensity change can be performed by considering the Stern-Volmer constant $\left(K_{\mathrm{SV}}\right)$. The $K_{\mathrm{SV}}$ value was calculated from the slopes of the curves. For $\mathrm{Co}^{2+}$ ion sensing, the S1-0.50 nanofiber membranes exhibited the highest $K_{\mathrm{SV}}$ value of

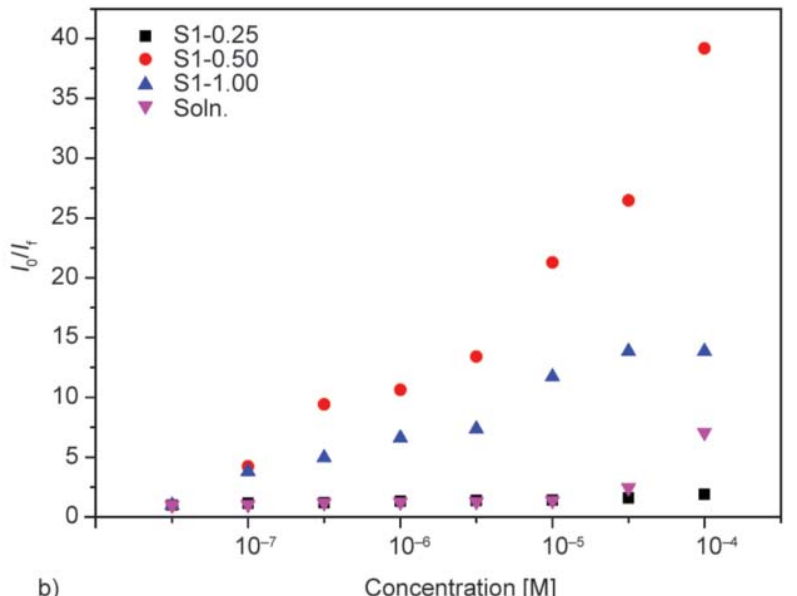

b)

Concentration [M]

Figure 7. PL spectra of S1-0.25, S1-0.5, S1-1.0 ES nanofiber membranes and BPDO in $\mathrm{MeOH}$ after the addition of (a) $\mathrm{Co}^{2+}$ and (b) $\mathrm{Cu}^{2+}$ ions at concentrations ranging from $10^{-7}$ to $10^{-4} \mathrm{M}$. ${ }^{*}$ Soln: BPDO in MeOH solution. 
$(10.35 \pm 0.16) \cdot 10^{4} \mathrm{M}^{-1}$, whereas the S1-0.25 and S1-1.0 membranes exhibited $K_{\mathrm{SV}}$ values of $(1.65 \pm 0.08) \cdot 10^{4}$ and $(6.13 \pm 0.12) \cdot 10^{4} \mathrm{M}^{-1}$ respectively. By comparison, quenching by BPDO in solution was associated with a $K_{\mathrm{SV}}$ value of $(8.25 \pm 0.06) \cdot 10^{4} \mathrm{M}^{-}$. This $K_{\mathrm{SV}}$ value from BPDO in solution is close to that of the S1-0.5 nanofiber membranes, which could be attributed to both easy diffusion and high reactivity of BPDO and $\mathrm{Co}^{2+}$ ions in the material. At $10^{-4} \mathrm{M}$ ion concentrations, quenching dramatically increased, which was not consistent for lower concentrations, seen in Figure 7a. This also validates the higher reactivities of BPDO with increased $\mathrm{Co}^{2+}$ concentrations. The S1-0.25 nanofiber membranes yielded the highest $K_{\mathrm{SV}}$ value, establishes that S1-0.5 is more sensitive than S1-0.25 and S1-1.0 nanofiber membranes (by 6.3 and 1.7 times, respectively). The fact that the S1-0.50 membranes exhibit a higher $K_{\mathrm{SV}}$ value than S1-1.0, despite the latter containing a higher amount of BPDO, might arise from aggregation by BPDO at the fiber surface of S1-1.0. This aggregation could hinder the formation of $\mathrm{Co}^{2+}$ ion complexes.

With respect to $\mathrm{Cu}^{2+}$ sensing, the S1-0.50 nanofiber membranes have a $K_{\mathrm{Sv}}$ value of $(31.88 \pm 0.08) \cdot 10^{4} \mathrm{M}$ that indicates high sensitivity. The S1-0.25 and S1-1.0 membranes have $K_{\mathrm{Sv}}$ values of $(0.71 \pm 0.12)$ and $(10.10 \pm 0.08) \cdot 10^{4} \mathrm{M}$, which are 45 and 3 times lower than that of the S1-0.50 membranes, respectively. Nanofiber membranes exhibited similar trends for sensing $\mathrm{Cu}^{2+}$ ions as for $\mathrm{Co}^{2+}$ ions. The S1-0.25 nanofiber membranes have the lowest amount of BPDO and the lowest $K_{\mathrm{SV}}$ value. The major decrease of $K_{\mathrm{SV}}$ value from $\mathrm{S} 1-0.50$ to $\mathrm{S} 1-1.0$ membranes still supports the aggregation of immobilized BPDO molecules on the nanofiber surface. BPDO in solution exhibits a lower $K_{\mathrm{SV}}$ value of $(5.52 \pm 0.09) \cdot 10^{4} \mathrm{M}$ that indicates the formation of non-fluorescent complexes to lesser degrees than that for S1-0.5 nanofiber membranes. The enhanced sensitivity of the S1-0.5 membrane is expected because of the higher surface area available for reaction with an optimal amount of BPDO.

\subsection{Reversibility and stability of the S1-0.5 ES nanofiber membranes}

The reversibility and stability of S1-0.5 ES nanofiber membranes were investigated by regeneration experiments with ethylenediaminetetraacetic acid (EDTA) $[3,58]$. Figure 8 shows that the S1-0.5 nanofiber

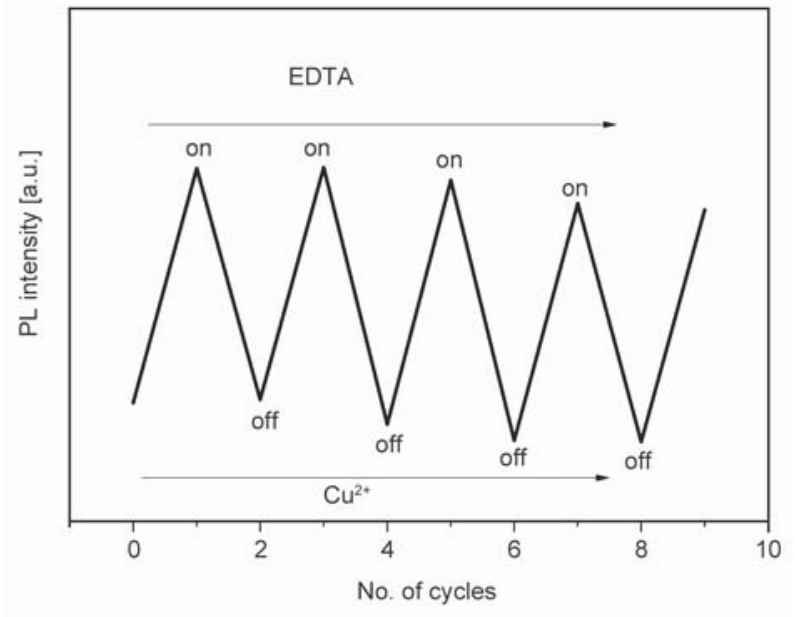

Figure 8. Reversibility of $\mathrm{Cu}^{2+}$ dependent 'on-off-on' fluorescence intensity profiles for S1-0.5 ES nanofiber membranes.

membranes exhibit reversible quenching/recovery behaviors by alternately treatments with $\mathrm{Cu}^{2+}$ ions $10^{-4} \mathrm{M}$ and EDTA. Initially, the addition of $\mathrm{Cu}^{2+}$ ion considerably quenches the fluorescence, which seems like switching off, but subsequently adding EDTA causes the fluorescence to rapidly recover similar like switching on. This on/off switch-like behavior of the fluorescence emission can be repeated at least five times, as shown in Figure 8. This originates from the strong chelation of $\mathrm{Cu}^{2+}$ ion by EDTA that regenerates fluorescence. After the third cycle, there is a slight decrease of fluorescence that may arise from retained $\mathrm{Cu}^{2+}$ ions. These nanofiber membranes nonetheless exhibit stable and reversible behaviors. The successful regeneration by EDTA suggests that S1-0.5 nanofiber membranes can be reused and recycled, which is advantageous for real-time metal ion sensing.

\subsection{Schematic of S1-0.5 ES nanofiber membranes for sensing applications}

Figure 9a shows the schematic illustration of S1-0.5 nanofiber membrane in a cuvette, as tested during experiments here. It is anticipated that the BPDO molecules interact with the nanofibers by $\mathrm{H}$-bonding. When water without $\mathrm{Co}^{2+}$ and $\mathrm{Cu}^{2+}$ ions enter into the fiber, the highest PL intensity can be observed. At this condition, the fluorescence is responsible for the BPDO molecules only, which exhibits maximum peak intensity at $469 \mathrm{~nm}$. Figure $9 \mathrm{~b}$ shows the chelation of BPDO molecules with $\mathrm{Co}^{2+}$ and $\mathrm{Cu}^{2+}$ ions within the nanofiber membranes. When the water contaminated with $\mathrm{Co}^{2+}$ and $\mathrm{Cu}^{2+}$ ions invades the 

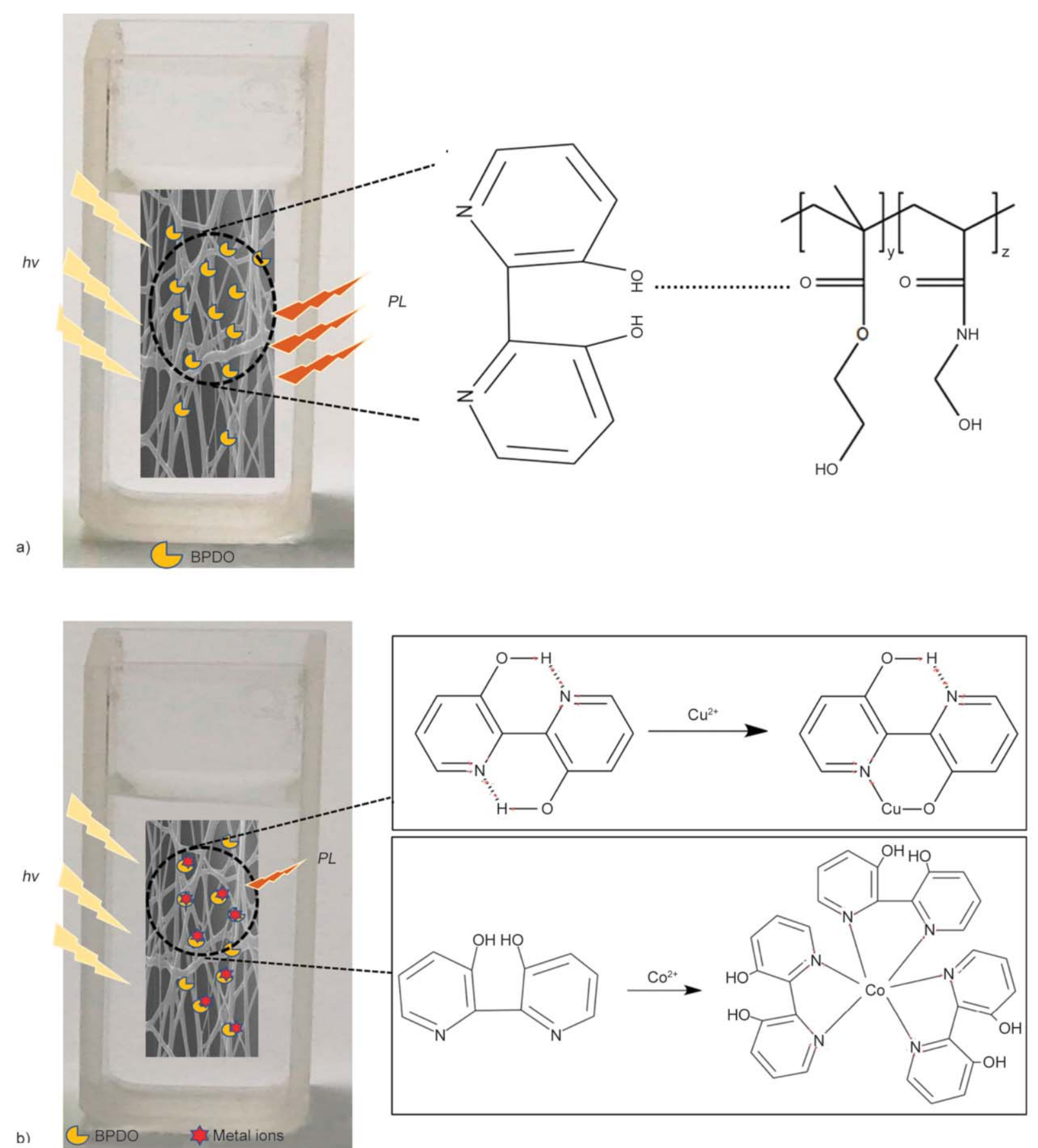

Figure 9. Schematic illustration of the (a) interaction of BPDO molecule with S1-0.5 in pure water, and (b) chelation of metal ions with BPDO.

nanofiber membranes, these chelation reactions occur. The chelation of metal ions by BPDO molecules within the nanofiber membranes caused fluorescence quenching that depended on the concentration of ions. The chelation reactions between BPDO and $\mathrm{Cu}^{2+}$ or $\mathrm{Co}^{2+}$ ions are illustrated in the schematic diagram as $\mathrm{Cu}^{2+}$ reacts with a single BPDO molecule and $\mathrm{Co}^{2+}$ reacts with three BPDO molecules through $\mathrm{N}$ atoms. A comparative study with the reported research results was carried out and shown in Table 2. Different sensing probes (such as BPDO and monoboronic acid conjugated rhodamine) have been developed to sense $\mathrm{Cu}^{2+}$ in solution [10, 70]. The sensing of $\mathrm{Hg}^{2+}$ by a rhodamine derivative sensing probe: RhBN2AM can be immobilized on copolymers poly(NIPAAmco-NMA-co-RhBN2AM) or poly(HEMA-co-NMAco-RhBN2AM) [57, 58]. Most studies have reported on the detection of single metal ions, regardless of the host matrix and sensing probes $[1,3,12,19,33$, 59]. Jaiswal studied on multi-metal ions detection $\left(\mathrm{Hg}^{2+}, \mathrm{Ag}+, \mathrm{Pb}^{2+}\right.$ ions) using $\mathrm{ZnS}$ Q-dot hosted by chitosan film [22]. Although many studies on $\mathrm{Cu}^{2+}$ 
Table 2. Comparison of research works on metal ion sensing.

\begin{tabular}{|c|c|c|c|c|c|}
\hline Materials & Form of material & Sensing probe & Detected metals & Range of detection & Ref. \\
\hline BPDO & Solution & BPDO & $\mathrm{Cu}^{2+}$ & $0-3.3 \cdot 10^{-6} \mathrm{M}$ & [70] \\
\hline $\begin{array}{l}\text { Monoboronic acid conjugated } \\
\text { rhodamine }\end{array}$ & Solution & $\begin{array}{l}\text { Monoboronic acid } \\
\text { conjugated rhodamine }\end{array}$ & $\mathrm{Cu}^{2+}$ & $3 \cdot 10^{-4} \mathrm{M}$ & [10] \\
\hline $\begin{array}{l}\text { Poly(NIPAAm-co-NMA-co- } \\
\text { RhBN2AM) }\end{array}$ & ES nanofiber & RhBN2AM & $\mathrm{Hg}^{2+}$ & $10^{-3}-10^{-7} \mathrm{M}$ & [57] \\
\hline $\begin{array}{l}\text { Poly(HEMA-co-NMA-co- } \\
\text { RhBN2AM) }\end{array}$ & ES nanofiber & RhBN2AM & $\mathrm{Hg}^{2+}$ & $10^{-3}-10^{-7} \mathrm{M}$ & {$[58]$} \\
\hline $\begin{array}{l}\text { 1,10-phenanthroline doped } \\
\text { poly(NIPAAm-co-NMA) }\end{array}$ & ES nanofiber & 1,10-phenanthroline & $\mathrm{Cu}^{2+}$ & $10^{-3}-10^{-7} \mathrm{M}$ & [1] \\
\hline $\begin{array}{l}\text { (Bpy-F-bpy) blended } \\
\text { poly(HEMA-co-NMA) }\end{array}$ & ES nanofiber & Bpy-F-bpy & $\mathrm{Zn}^{2+}, \mathrm{Hg}^{2+}, \mathrm{Cu}^{2+}$ & $5 \cdot 10^{-3}-5 \cdot 10^{-7} \mathrm{M}$ & {$[62]$} \\
\hline $\begin{array}{l}\text { Poly(NIPAAm-co-NMA-co- } \\
\text { RHPMA) }\end{array}$ & ES nanofiber & RHPMA & $\mathrm{Cu}^{2+}$ & $2 \cdot 10^{-4}-10^{-6} \mathrm{M}$ & [3] \\
\hline $\begin{array}{l}\text { ZnS Q-dot-impregnated chi- } \\
\text { tosan }\end{array}$ & Film & ZnS-Q dot & $\mathrm{Hg}^{2+}, \mathrm{Ag}^{+}, \mathrm{Pb}^{2+}$ & $2 \cdot 10^{-5} \mathrm{M}$ & {$[22]$} \\
\hline $\begin{array}{l}\text { Triazine bridged polymer } \\
\text { DTMSPV }\end{array}$ & $\begin{array}{l}\text { Micelle-like nano- } \\
\text { strucutre }\end{array}$ & DTMSPV & $\mathrm{Al}^{3+}$ & $0-3.6 \cdot 10^{-4} \mathrm{M}$ & [12] \\
\hline Poly(MMA-co-NAAP) & ES nanofiber and film & NAAP & $\mathrm{Cu}^{2+}$ & $2 \cdot 10^{-5}-1 \cdot 10^{-6} \mathrm{M}$ & [59] \\
\hline $\begin{array}{l}\text { Polyfluorene derivative } \\
\left(\mathrm{PF}-\mathrm{NH}_{2}\right)\end{array}$ & Film & $\mathrm{PF}$ & $\mathrm{Cu}^{2+}$ & $0-5 \cdot 10^{-5} \mathrm{M}$ & [33] \\
\hline QIOEt modified Si nanowires & Nanowire & QIOEt & $\mathrm{Cu}^{2+}$ & $0-10^{-6} \mathrm{M}$ & [19] \\
\hline Poly(PAA-co-PM) & ES nanofiber & PM & $\mathrm{Fe}^{3+}, \mathrm{Hg}^{2+}$ & $0-5.9 \cdot 10^{-6} \mathrm{M}$ & [60] \\
\hline $\begin{array}{l}\text { BPDO blended } \\
\text { poly(HEMA- } c o-\mathrm{NMA})\end{array}$ & ES nanofiber & BPDO & $\mathrm{Cu}^{2+}, \mathrm{Co}^{2+}$ & $10^{-4}-10^{-7} \mathrm{M}$ & Present work \\
\hline
\end{tabular}

sensing have been carried out, there is very little work on $\mathrm{Co}^{2+}$ ion sensing. However, poly(HEMA-coNMA)/BPDO exhibits unique multi-metal ion sensing capabilities $\left(\mathrm{Cu}^{2+}, \mathrm{Co}^{2+}\right)$, detection range, and practical application feasibility with recyclability.

\section{Conclusions}

New ES nanofiber membranes with high sensitivities for detecting $\mathrm{Co}^{2+}$ and $\mathrm{Cu}^{2+}$ ions with on/off switchable behaviors were prepared by electrospinning the mixture of poly(HEMA-co-NMA) random bi-copolymer with BPDO. Integrating different ratios of BPDO into the cross-linked ES nanofiber membranes resulted in different metal ion sensing capacities. Increasing the BPDO concentration in the solution similarly increased the sensing capacity of metal ions. Various changes in the fluorescence emission quenching and optical absorbance band shifts of ES nanofiber membranes occurred after exposure to metal ions. Quantitative comparisons of these optical changes were performed by using Stern-Volmer constant ( $K_{\mathrm{SV}}$ value), which revealed that the S1-0.5 nanofiber membranes demonstrated high and consistent sensitivity for both $\mathrm{Co}^{2+}$ and $\mathrm{Cu}^{2+}$ ions $(10.35 \pm 0.16) \cdot 10^{4}$ and $(31.88 \pm 0.08) \cdot 10^{4} \mathrm{M}^{-1}$, respectively. This material also showed a stable morphology in an aqueous solution. Moreover, the nanofiber membrane exhibits reversible on-off switchable fluorescence changes with $\mathrm{Cu}^{2+}$ ions, which proves the reusability of this material in practical applications. These results demonstrate the application potential of S1-0.5 ES nanofiber membrane in real-time sensing of $\mathrm{Co}^{2+}$ and $\mathrm{Cu}^{2+}$ ions.

\section{Acknowledgements}

The authors appreciate the financial support to this research by The Ministry of Science and Technology, Taiwan under grant number: MOST 108-2221-E-011-040-MY2 and MOST 108-2218-E-011-012.

\section{References}

[1] Lin H-J., Chen C-Y.: Thermo-responsive electrospun nanofibers doped with 1,10-phenanthroline-based fluorescent sensor for metal ion detection. Journal of Materials Science, 51, 1620-1631 (2016). https://doi.org/10.1007/s10853-015-9485-Z

[2] Gál J., Hursthouse A., Tatner P., Stewart F., Welton R.: Cobalt and secondary poisoning in the terrestrial food chain: Data review and research gaps to support risk assessment. Environment International, 34, 821-838 (2008).

https://doi.org/10.1016/j.envint.2007.10.006 
[3] Wu W-C., Lai H-J.: Preparation of thermo-responsive electrospun nanofibers containing rhodamine-based fluorescent sensor for $\mathrm{Cu}^{2+}$ detection. Journal of Polymer Research, 23, 223/1-223/11 (2016).

https://doi.org/10.1007/s10965-016-1115-1

[4] Deshmukh M. A., Gicevicius M., Ramanaviciene A., Shirsat M. D., Viter R., Ramanavicius A.: Hybrid electrochemical/electrochromic $\mathrm{Cu}$ (II) ion sensor prototype based on PANI/ITO-electrode. Sensors and Actuators B: Chemical, 248, 527-535 (2017).

https://doi.org/10.10116/j.snb.2017.03.167

[5] Hong W., Li W., Hu X., Zhao B., Zhang F., Zhang D.: Highly sensitive colorimetric sensing for heavy metal ions by strong polyelectrolyte photonic hydrogels. Journal of Materials Chemistry, 21, 17193-17201 (2011). https://doi.org/10.1039/C1JM12785C

[6] Liu B., Yu W-L., Pei J., Liu S-Y., Lai Y-H., Huang W.: Design and synthesis of bipyridyl-containing conjugated polymers: Effects of polymer rigidity on metal ion sensing. Macromolecules, 34, 7932-7940 (2001). https://doi.org/10.1021/ma0106651

[7] Ojida A., Takashima I., Kohira T., Nonaka H., Hamachi I.: Turn-on fluorescence sensing of nucleoside polyphosphates using a xanthene-based $\mathrm{Zn}$ (II) complex chemosensor. Journal of the American Chemical Society, 130, 12095-12101 (2008).

https://doi.org/10.1021/ja803262w

[8] Carter K. P., Young A. M., Palmer A. E.: Fluorescent sensors for measuring metal ions in living systems. Chemical Reviews, 114, 4564-4601 (2014).

https://doi.org/10.1021/cr400546e

[9] Bag B., Pal A.: Water induced chromogenic and fluorogenic signal modulation in a bi-fluorophore appended acyclic amino-receptor system. Organic and Biomolecular Chemistry, 9, 915-925 (2011).

https://doi.org/10.1039/C0OB00238K

[10] Swamy K. M. K., Ko S-K., Kwon S. K., Lee H. N., Mao C., Kim J-M., Lee K-H., Kim J., Shin I., Yoon J.: Boronic acid-linked fluorescent and colorimetric probes for copper ions. Chemical Communications, 45, 59155917 (2008). https://doi.org/10.1039/B814167C

[11] Zeng L., Miller E. W., Pralle A., Isacoff E. Y., Chang C. J.: A selective turn-on fluorescent sensor for imaging copper in living cells. Journal of the American Chemical Society, 128, 10-11 (2006).

https://doi.org/10.1021/ja055064u

[12] You J., Kim J., Park T., Kim B., Kim E.: Highly fluorescent conjugated polyelectrolyte nanostructures: Synthesis, self-assembly, and $\mathrm{Al}^{3+}$ ion sensing. Advanced Functional Materials, 22, 1417-1424 (2012). https://doi.org/10.1002/adfm.201102309

[13] Kim H. N., Guo Z., Zhu W., Yoon J., Tian H.: Recent progress on polymer-based fluorescent and colorimetric chemosensors. Chemical Society Reviews, 40, 79-93 (2011). https://doi.org/10.1039/C0CS00058B
[14] Shiraishi Y., Miyamoto R., Zhang X., Hirai T.: Rhodamine-based fluorescent thermometer exhibiting selective emission enhancement at a specific temperature range. Organic Letters, 9, 3921-3924 (2007). https://doi.org/10.1021/o1701542m

[15] Thomas S. W., Joly G. D., Swager T. M.: Chemical sensors based on amplifying fluorescent conjugated polymers. Chemical Reviews, 107, 1339-1386 (2007). https://doi.org/10.1021/cr0501339

[16] McQuade D. T., Pullen A. E., Swager T. M.: Conjugated polymer-based chemical sensors. Chemical Reviews, 100, 2537-2574 (2000).

https://doi.org/10.1021/cr9801014

[17] Liu D., Wang Z., Jiang X.: Gold nanoparticles for the colorimetric and fluorescent detection of ions and small organic molecules. Nanoscale, 3, 1421-1433 (2011). https://doi.org/10.1039/C0NR00887G

[18] Kim H. J., Lee S. J., Park S. Y., Jung J. H., Kim J. S.: Detection of $\mathrm{Cu}^{\mathrm{II}}$ by a chemodosimeter-functionalized monolayer on mesoporous silica. Advanced Materials, 20, 3229-3234 (2008). https://doi.org/10.1002/adma.200800246

[19] Mu L., Shi W., Chang J. C., Lee S-T.: Silicon nanowires-based fluorescence sensor for $\mathrm{Cu}$ (II). Nano Letters, 8, 104-109 (2008). https://doi.org/10.1021/n1072164k

[20] Lou Y., Zhao Y., Chen J., Zhu J-J.: Metal ions optical sensing by semiconductor quantum dots. Journal of Materials Chemistry C, 2, 595-613 (2014). https://doi.org/10.1039/C3TC31937G

[21] Wu P., Zhao T., Wang S., Hou X.: Semicondutor quantum dots-based metal ion probes. Nanoscale, 6, 43-64 (2014). https://doi.org/10.1039/C3NR04628A

[22] Jaiswal A., Ghosh S. S., Chattopadhyay A.: Quantum dot impregnated-chitosan film for heavy metal ion sensing and removal. Langmuir, 28, 15687-15696 (2012). https://doi.org/10.1021/la3027573

[23] Kaes C., Katz A., Hosseini M. W.: Bipyridine: The most widely used ligand. A review of molecules comprising at least two 2,2'-bipyridine units. Chemical Reviews, 100, 3553-3590 (2000). https://doi.org/10.1021/cr990376z

[24] He S., Iacono S. T., Budy S. M., Dennis A. E., Smith D. W., Smith R. C.: Photoluminescence and ion sensing properties of a bipyridyl chromophore-modified semifluorinated polymer and its metallopolymer derivatives. Journal of Materials Chemistry, 18, 1970-1976 (2008). https://doi.org/10.1039/B713458D

[25] Mihsen H. H., Shareef N. K.: Synthesis, characterization of mixed- ligand complexes containing 2,2-bipyridine and 3-aminopropyltriethoxysilane. Journal of Physics: Conference Series, 1032, 012066/1-012066/12 (2018).

https://doi.org/10.1088/1742-6596/1032/1/012066 
[26] Yasuda T., Yamamoto T.: Synthesis and characterization of new luminescent 1,10-phenanthroline- and pyridinecontaining $\pi$-conjugated polymers. Their optical response to protic acid, $\mathrm{Mn}^{+}$, and solvents. Macromolecules, 36, 7513-7519 (2003).

https://doi.org/10.1021/ma030280d

[27] Bulska H.: Intramolecular cooperative double proton transfer in [2,2'-bipyridyl]-3,3'-diol. Chemical Physics Letters, 98, 398-402 (1983).

https://doi.org/10.1016/0009-2614(83)80231-0

[28] Abou-Zied O. K.: Steady-state and time-resolved spectroscopy of 2,2'-bipyridine-3,3'-diol in solvents and cyclodextrins: Polarity and nanoconfinement effects on tautomerization. The Journal of Physical Chemistry B, 114, 1069-1076 (2010). https://doi.org/10.1021/jp909528e

[29] Nag T. N., Das T., Mondal S., Maity A., Purkayastha P.: Promoting the 'water-wire' mechanism of double proton transfer in [2,2'-bipyridyl]-3, 3'-diol by porous gold nanoparticles. Physical Chemistry Chemical Physics, 17, 6572-6576 (2015).

https://doi.org/10.1039/C4CP03968H

[30] Rurack K., Resch U., Senoner M., Dähne S.: A new fluorescence probe for trace metal ions: Cation-dependent spectroscopic properties. Journal of Fluorescence, 3, 141-143 (1993).

https://doi.org/10.1007/BF00862731

[31] Rurack K., Radeglia R.: Transition metal ion complexes of 2,2'-bipyridyl-3,3'-diol and 2,2'-bipyridyl-3-ol: Spectroscopic properties and solvent-dependent binding modes. European Journal of Inorganic Chemistry, 2000, 2271-2282 (2000).

https://doi.org/10.1002/10990682(200010)2000:10<2271::AID-EJIC2271>3.0.CO;2-3

[32] Mandal S., Ghosh S., Banerjee C., Kuchlyan J., Sarkar N.: Unique photophysical behavior of 2,2'-bipyridine3,3'-diol in dmso-water binary mixtures: Potential application for fluorescence sensing of $\mathrm{Zn}^{2+}$ based on the inhibition of excited-state intramolecular double proton transfer. The Journal of Physical Chemistry B, 117, 12212-12223 (2013).

https://doi.org/10.1021/jp406853r

[33] Lv F., Feng X., Tang H., Liu L., Yang Q., Wang S.: Development of film sensors based on conjugated polymers for copper (II) ion detection. Advanced Functional Materials, 21, 845-850 (2011). https://doi.org/10.1002/adfm.201001738

[34] Basabe-Desmonts L., Reinhoudt D. N., Crego-Calama M.: Design of fluorescent materials for chemical sensing. Chemical Society Reviews, 36, 993-1017 (2007). https://doi.org/10.1039/B609548H

[35] Malcik N., Oktar O., Ozser M., Caglar P., Bushby L., Vaughan A., Kuswandi B., Narayanaswamy R.: Immobilised reagents for optical heavy metal ions sensing. Sensors and Actuators B: Chemical, 53, 211-221 (1998).

https://doi.org/10.1016/S0925-4005(99)00004-0
[36] Kuo C-C., Tung Y-C., Chen W-C.: Morphology and pH sensing characteristics of new luminescent electrospun fibers prepared from poly(phenylquinoline)-blockpolystyrene/polystyrene blends. Macromolecular Rapid Communications, 31, 65-70 (2010). https://doi.org/10.1002/marc.200900566

[37] Fu G-D., Xu L-Q., Yao F., Li G-L., Kang E-T.: Smart nanofibers with a photoresponsive surface for controlled release. ACS Applied Materials and Interfaces, 1, 2424-2427 (2009). https://doi.org/10.1021/am900526u

[38] Kuo C-C., Lin C-H., Chen W-C.: Morphology and photophysical properties of light-emitting electrospun nanofibers prepared from poly(fluorene) derivative/PMMA blends. Macromolecules, 40, 6959-6966 (2007). https://doi.org/10.1021/ma0711821

[39] Reneker D. H., Chun I.: Nanometre diameter fibres of polymer, produced by electrospinning. Nanotechnology, 7, 216-223 (1996). https://doi.org/10.1088/0957-4484/7/3/009

[40] Liu L., Xu W., Ding Y., Agarwal S., Greiner A., Duan G.: A review of smart electrospun fibers toward textiles. Composites Communications, 22, 100506/1-100506/20 (2020).

https://doi.org/10.1016/j.coco.2020.100506

[41] Jiang S., Chen Y., Duan G., Mei C., Greiner A., Agarwal S.: Electrospun nanofiber reinforced composites: A review. Polymer Chemistry, 9, 2685-2720 (2018). https://doi.org/10.1039/C8PY00378E

[42] Zhao L., Duan G., Zhang G., Yang H., He S., Jiang S.: Electrospun functional materials toward food packaging applications: A review. Nanomaterials, 10, 150/1150/32 (2020). https://doi.org/10.3390/nano10010150

[43] Chen Y-Y., Kuo C-C., Chen B-Y., Chiu P-C., Tsai P-C.: Multifunctional polyacrylonitrile- $\mathrm{ZnO} / \mathrm{Ag}$ electrospun nanofiber membranes with various $\mathrm{ZnO}$ morphologies for photocatalytic, UV-shielding, and antibacterial applications. Journal of Polymer Science Part B: Polymer Physics, 53, 262-269 (2015). https://doi.org/10.1002/polb.23621

[44] Babel A., Li D., Xia Y., Jenekhe S. A.: Electrospun nanofibers of blends of conjugated polymers: Morphology, optical properties, and field-effect transistors. Macromolecules, 38, 4705-4711 (2005). https://doi.org/10.1021/ma047529r

[45] Wu C., Chou M.: Acoustic-electric conversion and piezoelectric properties of electrospun polyvinylidene fluoride/silver nanofibrous membranes. Express Polymer Letters, 14, 103-114 (2020). https://doi.org/10.3144/expresspolymlett.2020.10

[46] Wu C-M., Chou M-H., Zeng W-Y.: Piezoelectric response of aligned electrospun polyvinylidene fluoride/ carbon nanotube nanofibrous membranes. Nanomaterials, 8, 420/1-420/13 (2018). https://doi.org/10.3390/nano8060420 
[47] Naseem S., Wu C-M., Xu T-Z., Lai C-C., Rwei S-P.: Oil-water separation of electrospun cellulose triacetate nanofiber membranes modified by electrophoretically deposited $\mathrm{TiO}_{2}$ /graphene oxide. Polymers, 10, 746/1746/14 (2018).

https://doi.org/10.3390/polym10070746

[48] Naseem S., Wu C-M., Chala T. F.: Photothermal-responsive tungsten bronze/recycled cellulose triacetate porous fiber membranes for efficient light-driven interfacial water evaporation. Solar Energy, 194, 391-399 (2019).

https://doi.org/10.1016/j.solener.2019.10.084

[49] Chala T. F., Wu C-M., Chou M-H., Guo Z-L.: Melt electrospun reduced tungsten oxide/polylactic acid fiber membranes as a photothermal material for light-driven interfacial water evaporation. ACS Applied Materials and Interfaces, 10, 28955-28962 (2018).

https://doi.org/10.1021/acsami.8b07434

[50] Wu T., Ding M., Shi C., Qiao Y., Wang P., Qiao R., Wang X., Zhong J.: Resorbable polymer electrospun nanofibers: History, shapes and application for tissue engineering. Chinese Chemical Letters, 31, 617-625 (2020). https://doi.org/10.1016/j.cclet.2019.07.033

[51] Chen Y., Sui L., Fang H., Ding C., Li Z., Jiang S., Hou H.: Superior mechanical enhancement of epoxy composites reinforced by polyimide nanofibers via a vacuum-assisted hot-pressing. Composites Science and Technology, 174, 20-26 (2019).

https://doi.org/10.1016/j.compscitech.2019.02.012

[52] Zhang N., Qiao R., Su J., Yan J., Xie Z., Qiao Y., Wang $\mathrm{X}$., Zhong J.: Recent advances of electrospun nanofibrous membranes in the development of chemosensors for heavy metal detection. Small, 13, 1604293/11604293/18 (2017).

https://doi.org/10.1002/smll.201604293

[53] Liu L., Bakhshi H., Jiang S., Schmalz H., Agarwal S.: Composite polymeric membranes with directionally embedded fibers for controlled dual Actuation. Macromolecular Rapid Communications, 39, 1800082/11800082/7 (2018).

https://doi.org/10.1002/marc.201800082

[54] Jiang S., Helfricht N., Papastavrou G., Greiner A., Agarwal S.: Low-density self-assembled poly( $N$-isopropyl acrylamide) sponges with ultrahigh and extremely fast water uptake and release. Macromolecular Rapid Communications, 39, 1700838/1-1700838/7 (2018). https://doi.org/10.1002/marc.201700838

[55] Duan G., Bagheri A. R., Jiang S., Golenser J., Agarwal S., Greiner A.: Exploration of macroporous polymeric sponges as drug carriers. Biomacromolecules, 18, 3215-3221 (2017). https://doi.org/10.1021/acs.biomac.7b00852

[56] Jiang S., Cheong J. Y., Nam J. S., Kim I-D., Agarwal S., Greiner A.: High-density fibrous polyimide sponges with superior mechanical and thermal properties. ACS Applied Materials and Interfaces, 12, 19006-19014 (2020).

https://doi.org/10.1021/acsami.0c02004
[57] Chen B-Y., Lung Y-C., Kuo C-C., Liang F-C., Tsai T-L., Jiang D-H., Satoh T., Jeng R-J.: Novel multifunctional luminescent electrospun fluorescent nanofiber chemosensor-filters and their versatile sensing of $\mathrm{pH}$, temperature, and metal ions. Polymers, 10, 1259/1-1259/16 (2018).

https://doi.org/10.3390/polym10111259

[58] Chen B-Y., Kuo C-C., Cho C-J., Liang F-C., Jeng R-J.: Novel fluorescent chemosensory filter membranes composed of electrospun nanofibers with ultra-selective and reversible ph and $\mathrm{Hg}^{2+}$ sensing characteristics. Dyes and Pigments, 143, 129-142 (2017).

https://doi.org/10.1016/j.dyepig.2017.04.023

[59] Wang W., Yang Q., Sun L., Wang H., Zhang C., Fei X., Sun M., Li Y.: Preparation of fluorescent nanofibrous film as a sensing material and adsorbent for $\mathrm{Cu}^{2+}$ in aqueous solution via copolymerization and electrospinning. Journal of Hazardous Materials, 194, 185-192 (2011). https://doi.org/10.1016/j.jhazmat.2011.07.083

[60] Wang X., Drew C., Lee S-H., Senecal K. J., Kumar J., Samuelson L. A.: Electrospun nanofibrous membranes for highly sensitive optical sensors. Nano Letters, 2 , 1273-1275 (2002).

https://doi.org/10.1021/n1020216u

[61] Chaudhuri S., Wu C-M.: Switchable wettability of poly (NIPAAm-co-HEMA-co-NMA) coated PET fabric for moisture management. Polymers, 12, 100/1-100/15 (2020). https://doi.org/10.3390/polym12010100

[62] Hung C-C., Kuo C-C., Weng N-K., Wu W-C., Chen B-Y., Cho C-J., Hsu I-J., Chiu Y-C., Chen W-C.: Novel highly sensitive and reversible electrospun nanofibrous chemosensor-filters composed of poly(HEMA-coMNA) and bpy-F-bpy with metal-ion-modulated multicolor fluorescence emission. Polymer Journal, 48, 439-449 (2016).

https://doi.org/10.1038/pj.2015.127

[63] Chiu Y-C., Kuo C-C., Hsu J-C., Chen W-C.: Thermoresponsive luminescent electrospun fibers prepared from poly(DMAEMA-co-SA-co-StFl) multifunctional random copolymers. ACS Applied Materials and Interfaces, 2, 3340-3347 (2010). https://doi.org/10.1021/am100760a

[64] Chiu Y-C., Chen Y., Kuo C-C., Tung S-H., Kakuchi T., Chen W-C.: Synthesis, morphology, and sensory applications of multifunctional rod-coil-coil triblock copolymers and their electrospun nanofibers. ACS Applied Materials and Interfaces, 4, 3387-3395 (2012). https://doi.org/10.1021/am300315v

[65] Hsueh Y-H., Liaw W-C., Kuo J-M., Deng C-S., Wu C-H.: Hydrogel film-immobilized lactobacillus brevis RK03 for $\gamma$-aminobutyric acid production. International Journal of Molecular Sciences, 18, 2324/1-2324/13 (2017). https://doi.org/10.3390/ijms18112324 
[66] Bach L. G., Cao X. T., Islam R., Jeong Y. T., Kim J. S., Lim K. T.: Synthesis and characterization of multiwalled carbon nanotubes/poly(HEMA-co-MMA) by utilizing click chemistry. Journal of Nanoscience and Nanotechnology, 16, 2975-2978 (2016).

https://doi.org/10.1166/jnn.2016.11049

[67] Baishya P., Maji T. K.: Studies on effects of different cross-linkers on the properties of starch-based wood composites. ACS Sustainable Chemistry and Engineering, 2, 1760-1768 (2014). https://doi.org/10.1021/sc5002325

[68] Yang Z., Cao L., Li J., Lin J., Wang J.: Facile synthesis of $\mathrm{Cu}-\mathrm{BDC} / \mathrm{Poly}(\mathrm{N}$-methylol acrylamide) HIPE monoliths via $\mathrm{CO}_{2}$-in-water emulsion stabilized by metal-organic framework. Polymer, 153, 17-23 (2018).

https://doi.org/10.1016/j.polymer.2018.07.085
[69] Stephenson M. D., Hardie M. J.: Network structures with 2,2'-bipyridine-3,3'diol: A discrete Co(III) complex that forms a porous 3-d hydrogen bonded network, and $\mathrm{Cu}(\mathrm{II})$ coordination chains. CrystEngComm, 9, 496-502 (2007). https://doi.org/10.1039/B702509M

[70] Reynal A., Etxebarria J., Nieto N., Serres S., Palomares E., Vidal-Ferran A.: A bipyridine-based 'naked-eye' fluorimetric $\mathrm{Cu}^{2+}$ chemosensor. European Journal of Inorganic Chemistry, 2010, 1360-1365 (2010). https://doi.org/10.1002/ejic.200900887 